DEUTSCHE AKADEMIE DER WISSENSCHAFTEN ZU BERLIN SCHRIFTEN DES INSTITUTS FÜR GESCHICHTE

REIHE III: VORTRÄGE UND TAGUNGEN DES INSTITUTS FUR GESCHICHTE BAND 3

\author{
EBERHARD WÄCHTLER
}

\title{
ZUR GESCHICHTE DES KAMPFES DES BERGARBEITERVERBANDES IN SACHSEN
}

EVANGELISCHE ARBEITERVEREINE UND GELBE GEWERKSCHAFTEN ALS INSTRUMENTE DER ZECHENHERREN

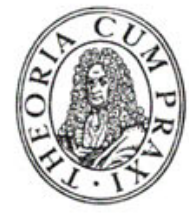

AKA DEM I E - VER LA G B ERLIN 1959 
Copyright 1959 by Akademie -Verlag GmbH, Berlin Alle Rechte vorbehalten

Erschienen im Akademie -Verlag GmbH, Berlin W 8, Mohrenstraße 39 Lizenz-Nr. $202 \cdot 100 / 123 / 59$

Satz, Druck und Bindung IV/2/14 - VEB Werkdruck Gräfenhainichen - 1014

Bestell- und Verlagsnummer 2083/III/3

Printed in Germany

ES $14 \mathrm{E}$ 